Research Article

\title{
Glechoma curviflora Volatile Oil from Palestine: Chemical Composition and Neuroprotective, Antimicrobial, and Cyclooxygenase Inhibitory Activities
}

\author{
Nawaf Al-Maharik (D), ${ }^{1}$ Nidal Jaradat $(D),{ }^{2}$ Mohammad Qneibi $(D),{ }^{3}$ \\ Murad N. Abualhasan $\mathbb{D}^{1},{ }^{1}$ and Nour Emwas ${ }^{3}$ \\ ${ }^{1}$ Department of Chemistry, Faculty of Sciences, An-Najah National University, Nablus, State of Palestine \\ ${ }^{2}$ Department of Pharmacy, Faculty of Medicine and Health Sciences, An-Najah National University, Nablus, State of Palestine \\ ${ }^{3}$ Department of Biomedical Sciences, Faculty of Medicine and Health Sciences, An-Najah National University, \\ Nablus, State of Palestine
}

Correspondence should be addressed to Nawaf Al-Maharik; n.maharik@najah.edu and Nidal Jaradat; nidaljaradat@najah.edu

Received 10 July 2020; Revised 10 October 2020; Accepted 11 November 2020; Published 24 November 2020

Academic Editor: Miguel Vilas-Boas

Copyright (c) 2020 Nawaf Al-Maharik et al. This is an open access article distributed under the Creative Commons Attribution License, which permits unrestricted use, distribution, and reproduction in any medium, provided the original work is properly cited.

\begin{abstract}
The rise of the emergence of microbial resistance of antibiotics, the dangerous side effects of nonsteroidal anti-inflammatory drugs, and noncompetent medications of Alzheimer's, Parkinson's, and other neurodegenerative diseases prompt scientists to search for phytochemicals that could be utilized in the remedy of lethal diseases. Glechoma curviflora (Boiss.) Kuntze (Nepeta curviflora) is a medicinal herb growing in the eastern parts of the Mediterranean Sea Basin and is widely consumed as a tea. The leaves of this plant have been traditionally used for the treatment of various infectious diseases. The current research was designed to identify the chemical composition of Glechoma curviflora (Boiss.) essential oil (EO) and to assess its antibacterial, antifungal, and cyclooxygenase inhibitory activities and the biophysical gating effect on AMPA receptors. Twenty phytochemicals were identified from G. curviflora leaves and flowers EO amounting to almost 100\% of the total constituents using GC-MS technique, of which 1,6-dimethylspiro[4.5]decane (27.51\%) 1, caryophyllene oxide (20.08\%) 2, and $\beta$-caryophyllene (18.28\%) 3 were the main constituents. The biophysical properties' effect from the plant extract on various AMPA-type receptors expressed in Human Embryonic Kidney (HEK293) cells was assessed by exploiting the whole-cell patch-clamp technique. Microdilution assay was adopted for assessing the antimicrobial property against eight virulent microbial strains whilst the cyclooxygenase inhibition effect was accomplished utilizing COX inhibitory screening colorimetric assay G. curviflora EO displayed potent activity against P. aeruginosa $(\mathrm{MIC}=1.25 \mu \mathrm{g} / \mathrm{mL}), S$. sonnei $(\mathrm{MIC}=3.12 \mu \mathrm{g} / \mathrm{mL})$, and $E$. coli $(\mathrm{MIC}=1.25 \mu \mathrm{g} / \mathrm{mL})$, compared with ciprofloxacin (positive control) and potent antibacterial activity against $S$. aureus, MRSA, S. sonnei, E. coli, and P. aeruginosa compared to Ampicillin (2nd positive control). It also showed anti-Candida $(\mathrm{MIC}=6.25 \mu \mathrm{g} / \mathrm{mL})$ and antimold $(\mathrm{MIC}=3.125 \mu \mathrm{g} / \mathrm{mL}) \mathrm{activities}$ compared with fluconazole (antifungal positive control). Likewise, our results showed an inhibition and biophysical impact of $G$. curviflora on all AMPARs subunits.
\end{abstract}

\section{Introduction}

The search for medications and dietary supplements derived from plants has accelerated in the last two decades. Botanists, phytochemists, microbiologists, and pharmacologists are combing the Earth searching for natural products that have therapeutic potentials [1]. Essential oils (EOs) are valuable natural plant products known for their therapeutic importance and have been widely employed in cosmetics, perfumes, foods, flavoring agents, and beverages industries [2].

Postsynaptic membranes expressing cation glutamatergic AMPA receptors (AMPARs) are implicated in various plasticity and synaptic transmissions. In the 
mammalian brain, the postsynaptic AMPARs are fundamentally essential in facilitating the predominantly fast excitatory transmission. Overactivated AMPARs trigger excitotoxicity, involved in numerous neurodegenerative severe illnesses such as AIDS encephalitis, Amyotrophic Lateral Sclerosis (ALS), Parkinson's, epilepsy, Huntington's, and other neurological disorders [3].

Microbial infections due to drug-resistant strains turn out to be one of the most serious intimidations to public health. Numerous health care systems and research centers, especially in developed countries, are relentlessly searching for alternative therapies to cure such infections. Herbal medicines are acknowledged to prevent infections as they are considered a better alternative to artificial drugs due to drugresistant pathogens [4].

Cyclooxygenase (COX-1 or COX-2) inhibitors, classified as NSAIDs-nonsteroidal anti-inflammatory drugs, are considered to be the most common medications for inflammatory diseases due to their effectiveness in the treatment of fever, redness, pain, and edema. Most of the used NSAIDs are associated with harmful side effects, including gastrointestinal ulcers, renal failure, and hepatic dysfunction $[5,6]$.

Glechoma curviflora (Boiss.) Kuntze (Nepeta curviflora) is a perennial aromatic herb growing in the eastern parts of the Mediterranean Sea Basin, which is widely consumed as a tea in Lebanon, Syria, Jordan, Turkey, and Palestine [7]. It is utilized for the treatment of diarrhea, bronchitis, fever, flu, colic, cough, colds, angina pectoris, and tachycardia. It is also used as antiseptic, diuretic, carminative, and sedative [8]. G. curviflora is utilized in folk medicine for curing different infectious and Alzheimer's disease and as an antipyretic agent [9]. The current study aims to identify and quantify the chemical components and to evaluate the antimicrobial, cyclooxygenase inhibitory, and neuroprotective effects of G. curviflora EO.

\section{Material and Methods}

2.1. Plant Collection and Essential Oil Extraction. The flowers and leaves of the G. curviflora plant were compiled from the Birzeit mountains in Palestine in May 2019. The taxonomical characterization was executed by Dr. Nidal Jaradat a pharmacognosist. The dried herbarium was kept at the Herbal Products Laboratory labeled as Pharm-PCT-1633 obtained from the voucher specimen code. After washing with distilled water, the leaves and flowers were left to dry in the shadow at a $25 \pm 2^{\circ} \mathrm{C}$ temperature and $55 \pm 5 \mathrm{RH}$ humidity for two weeks then powdered using a mechanical grinder and stored in paper bags [10]. The G. curviflora EO was extracted utilizing the Ultrasonic-Microwave apparatus according to the literature procedure [11]. A $1 \mathrm{~L}$ roundbottom flask containing $50 \mathrm{~g}$ of the dried plant powder and $0.5 \mathrm{~L}$ of distilled water was positioned in the apparatus and connected to the Clevenger apparatus. The microwave power was adjusted at $800 \mathrm{~W}$ and the extraction was executed at $90^{\circ} \mathrm{C}$ for $20 \mathrm{~min}$, where the same process was triplicated. The attained EO was dried using calcium chloride and stored at $2-8^{\circ} \mathrm{C}$. The dried plant sample provided
$0.905 \mathrm{~g}$ of a colorless oil in $1.81 \%$ yield average of the isolated EO.

2.2. GC-MS Qualitative and Quantitative Characterization of

G. curviflora EO Composition. The identification of G. curviflora EO components was accomplished using PerkinElmer Elite-5-MS fused-silica capillary column $(0.25 \mathrm{~mm} \times 30 \mathrm{~m}$, film thickness $0.25 \mu \mathrm{m})$, where helium was set at $1.1 \mathrm{~mL} / \mathrm{min}$ flow rate. The temperature of the injector was adjusted at $250^{\circ} \mathrm{C}$ with an initial temperature of $50^{\circ} \mathrm{C}$, initial hold $5 \mathrm{~min}$, and $\operatorname{ramp} 4.0^{\circ} \mathrm{C} / \mathrm{min}$ to $280^{\circ} \mathrm{C}$. The total running time was $62.50 \mathrm{~min}$ and the solvent delay was from 0 to $4.0 \mathrm{~min}$. MS scan time was from 4 to $62.5 \mathrm{~min}$, covering mass range 50.00 to $300.00 \mathrm{~m} / \mathrm{z}$. To cover a mass range of 50.00 to $300.00 \mathrm{~m} / \mathrm{z}$, the corresponding MS scan time range was 4 to $62.5 \mathrm{~min}$. Comparing the mass spectra of the G. curviflora EO to the reference spectra in the MS data Center of the National Institute of Standards and Technology, we identified the plant's components. Finally, by matching their Kovats retention indices with the values reported in the literature, the G. curviflora EO components were quantified $[12,13]$.

2.3. Neuroprotective Effect Assessment. Previous work from our laboratory provides a methodology for the DNA preparation, cDNA transient transfection, and cell culturing of HEK293 to express AMPARs (of the flip isoform) of different subunits [14-16]. Two days after the chemical mediated transfection procedure, we proceeded to assess the electrophysiological recordings of the green fluorescent protein cotransfected cells. Prior preparations included the replating of the cells on coverslips layered with laminin. The cells exhibiting a strong fluorescent image were selected to proceed via gigaseal. The $2-4 \mathrm{M} \Omega$ resistance patch electrodes were produced utilizing borosilicate glass. An integrated patch amplifier IPA (Sutter Instruments, Novato, CA, and SutterPatch Software v. 1.1.1 to digitize membrane currents for a short period) was employed to perform the whole-cell patch-clamp technique. The IPA was set at $22^{\circ} \mathrm{C}$, the sampling frequency at $10 \mathrm{kHz}$, and the low-pass filter set at $2 \mathrm{kHz}$, using a membrane potential of $-60 \mathrm{mV}$. The extracellular solution composed of $\mathrm{NaCl}(0.15 \mathrm{M}), \mathrm{KCl}(2.8 \mathrm{mM})$, $\mathrm{MgCl}_{2}(0.5 \mathrm{mM}), \mathrm{CaCl}_{2}(2.0 \mathrm{mM})$, and $\mathrm{NaOH}$ that was attuned to a $7.4 \mathrm{pH}$. The pipette solution comprised of $\mathrm{CsF}$ (0.11 M), CsCl $(30 \mathrm{mM}), 4 \mathrm{NaCl}(4 \mathrm{mM}), 0.5 \mathrm{CaCl}_{2}$ (0.5 mM), 10 Trypsin EDTA $(10 \mathrm{mM})$ solution B $(0.25 \%)$, EDTA $(0.05 \%)$, and 10 HEPES $(10 \mathrm{mM})$ which was adjusted to $\mathrm{pH} 7.2$ with $\mathrm{CsOH}$ was prepared. A double-barrel glass (theta tube), set at high-speed piezo solution switcher (Automate Scientific, Berkeley, CA), was employed for continuous wash of the cell from one opening whereas the other provides the currently tested compound to the cell. Pulses per $500 \mathrm{~ms}$ resulted in a $10-90 \%$ solution exchange whereby the velocity of this rate is calculated from the removal of the patch from the electrode. Amplitude was induced due to the ionic strength differences from different solutions. The desensitization was calculated after applying glutamate $(10 \mathrm{mM})$ for $500 \mathrm{~ms}$ while deactivation was 
applied for $20 \mathrm{~ms}$. The total number of trials per experiment was 5 cells to calculate the mean of inhibition, desensitization, and deactivation. The control was recordings for the biophysical properties of glutamate alone; the recordings before and after application of treatment must be indistinguishable to authenticate the effect of EO on the cell and confirm the health of the cell.

\subsection{Antimicrobial Activity}

2.4.1. Microbial Isolates. The tested microbial isolates including fungal strains and bacterial strains were provided by the American Type Culture Collection in addition to a selected multidrug resistance strain which was isolated at clinical locations in our region. The isolates comprised of three Gram-positive strains-Enterococcus faecium (ATCC 700221), Methicillin-Resistant Staphylococcus aureus (MRSA), and Staphylococcus aureus (ATCC 25923) - and three Gram-negative strains-Shigella sonnei (ATCC 25931), Pseudomonas aeruginosa (ATCC 27853), and Escherichia coli (ATCC 25922). The fungal isolates were Epidermophyton floccosum (ATCC 10231) and Candida albicans (ATCC 90028).

2.4.2. Antimicrobial Test. The well-diffusion assay was used for screening of the antimicrobial activity of G. curviflora EO. The bacterial suspension was formulated by the addition of selected colonies from agar culture to a test tube containing $5 \mathrm{~mL}$ of nutrient broth. Then, the turbidity of the sample was compared to that of McFarland nephelometer tube no. $0.5\left(1.5 \times 10^{8} \mathrm{CFU} / \mathrm{ml}\right)$. A $1 \mathrm{~mL}$ of the suspension was added to $2 \mathrm{~mL}$ of nutrient broth $\left(0.5 \times 10^{8} \mathrm{CFU} / \mathrm{ml}\right)$. G. curviflora EO underwent a sequential broth dilution technique to evaluate their minimum inhibitory concentration (MIC) for all tested microbial strains.

2.4.3. Determination of MIC. Micro broth dilution assay was utilized to evaluate the antimicrobial activity of G. curviflora EO. A $100 \mu \mathrm{L}$ of Mueller-Hinton broth was placed in each well of the microtitration plate, followed by the addition of $100 \mu \mathrm{L}$ of a suspension of EO in $2 \%$ aqueous DMSO $(50 \mu \mathrm{g} /$ $\mathrm{mL}$ ) into the first well which was mixed using the micropipette. $100 \mu \mathrm{L}$ from the first well was transferred to the next well. This process was replicated for the other 9 wells unlike the last well (\#11) that was labeled as a negative control for bacterial growth. The remaining solution from the $100 \mu \mathrm{L}$ was discharged after mixing, since the EO was not added to well number 12 that was labeled as the positive control. Thereafter, $1 \mu \mathrm{L}$ of a bacterial suspension (from $5 \times 10^{7} \mathrm{CFU}$ / $\mathrm{mL}$ bacterial suspension) was added to all wells excluding the negative control well \#11. In well number 12, the inoculated bacteria should grow because it does not contain the EO. After 24 incubation at $35^{\circ} \mathrm{C}$, the lowest concentration of G. curviflora EO that caused inhibition of the evident bacterial growth was identified as the MIC. G. curviflora EO was screened twice in each run $[17,18]$. The $2 \%$ DMSO solution was used as a positive control for every microbe separately to check the effect on each one (antimicrobial activity for DMSO was considered).

2.4.4. Determination of the Antiyeast Activity of G. curviflora EO. The MIC of the studied EO against Candida albicans was assessed employing broth microdilution assay as described in the literature $[19,20]$, where the MHB was replaced with RPMI1640.

(1) RPMI1640 Preparation. RPMI powder (1.04 g) was dissolved into $90 \mathrm{~mL}$ of sterile distilled water. Afterward, MOP ( $3.456 \mathrm{~g}$ ) was added to the solution. To adjust the $\mathrm{pH}$ of the solution to 7 , a $1 \mathrm{M} \mathrm{NaOH}$ aqueous solution was added. Finally, to reach a volume of $100 \mathrm{~mL}$, distilled and sterilized water was added to make up the difference. Using a $0.45 \mu \mathrm{m}$ syringe filter, the solution was sterilized at room temperature.

(2) Broth Microdilution. The first well consisted of $100 \mu \mathrm{L}$ of RPMI, 1640 broth media, and $100 \mu \mathrm{L}$ of G. curviflora EO homogenously mixed while the second well only contained $100 \mu \mathrm{L}$ of RPMI and 1640 broth media. From the first well, $100 \mu \mathrm{L}$ was extracted and supplemented to the second well. This process was replicated for the 10 following wells yet leaving the last well as a positive control with only RPMI1640 broth. The G. curviflora EO at concentrations of 0.065 to $55 \mu \mathrm{g} / \mathrm{mL}$ was dispensed in the microwells to assess its antifungal properties.

(3) Inoculum Preparation. Sabouraud dextrose agar was used to subculture Candida albicans which was set at $37^{\circ} \mathrm{C}$. After $24 \mathrm{~h}$ of subculturing, five colonies were added to $5 \mathrm{~mL}$ of $8.5 \%$ saline. To obtain a yeast concentration of $1 \times 10^{6}$ to $5 \times 10^{6} \mathrm{CFU} / \mathrm{mL}$, we accustomed 0.5 as the cell density by McFarland's standard where the absorbance was set at $625 \mathrm{~nm}$ of 0.08 to 0.1 . To achieve $1 \times 10^{3}$ to $5 \times 10^{3} \mathrm{CFU} / \mathrm{mL}$, the suspension was diluted to 1:50 and then 1:20 using broth medium (RPMI1640 broth), of which $100 \mu \mathrm{L}$ to each well except that of the negative control of yeast growth (well \#11). After $48 \mathrm{~h}$ incubation of the inoculated plates at $35^{\circ} \mathrm{C}$ for $48 \mathrm{~h}$, a $0.5-2.5 \times 10^{3}$ colony-forming units $(\mathrm{CFU}) / \mathrm{mL}$ concentration of microbial cells was obtained.

2.5. Antimold Activity. The agar dilution procedure was utilized to assess the anti-Epidermophyton floccosum mold activity for G. curviflora EO [19, 21]. The autoclave sterilized Sabouraud dextrose agar (SDA) was placed in tubes and kept in a water bath at $40^{\circ} \mathrm{C}$ to dilute G. curviflora EO. The range of concentration of the prepared G. curviflora EO used ranged from 0.025 to $25 \mu \mathrm{g} / \mathrm{mL}$. At a slanted position, the tubes were left to solidify at a $25^{\circ} \mathrm{C}$ temperature. After the preparation of suspension from the fresh culture of E. floccosum having similar turbidity to that of 0.5 McFarland standard, $20 \mu \mathrm{L}$ of it was added to each of the tubes. The positive control groups to mold consisted of SDA alone tubes. After 10 days of incubation at room temperature, the results were collected by identifying the concentration that ultimately inhibited the growth of 
E. floccosum which was labeled as the minimum inhibitory concentration.

2.6. Cyclooxygenase Inhibitory Activity. The EO effect on COX-1 (ovine) and COX-2 (human recombinant) enzymes was determined employing the COX inhibitor screening assay kit no. 560131 of Cayman Chemical (USA). The yellow product of this enzymatic reaction was assessed using a UVVisible-spectrophotometer (Janeway, 7300, UK) in a Microplate Reader (Bio-Rad, A112, Japan) at $415 \mathrm{~nm}$. The inhibitory assays were conducted at $\mathrm{EO}$ concentrations of 0.25 and $0.5 \mu \mathrm{g} / \mathrm{mL}$ with a commercial anti-inflammatory drug (celecoxib). The cyclooxygenase inhibitory activity of the tested product was assessed and calculated from the concentration-inhibition response curve via regression analysis to obtain an inhibited percentage of PGE2. The tested $\mathrm{EO}$ concentration resulted in $50 \%$ inhibition $\left(\mathrm{IC}_{50}\right)$ in the formation of PGE2 via COX-1 and COX-2 enzymes.

2.7. Data Analysis. The data obtained from the cyclooxygenase inhibitory assay were displayed as means \pm SD. $t$ test was performed to identify and quantify the chemical components while one-way ANOVA was utilized for electrophysiology recordings. The significant differences were considered at $p \leq 0.05$ for the cyclooxygenase inhibitory assay, while that for the electrophysiology section was considered at three levels: $0.05,0.01$, and 0.001 . At $50 \%$ $\left(\mathrm{IC}_{50}\right)$, the inhibitory concentration was calculated from BioDataFit HTP 1.2 (USA). Data obtained from whole-cell current recordings were expressed as means $\pm \mathrm{SD}$ of $n=5$ for the number of trials, performed at $-60 \mathrm{mV}, \mathrm{pH} 7.4$ at $22^{\circ} \mathrm{C}$, and analyzed using Wave Metrics, Inc. Igor Pro7.

\section{Results}

3.1. GC-MS Characterization of G. curviflora EO. GC-MS analysis of the EO of G. curviflora growing in Palestine revealed that 1,6-dimethylspiro[4.5]decane 1 (27.51\%), caryophyllene oxide 2 (20.08\%), and $\beta$-caryophyllene 3 $(18.28 \%)$ were the major constituents (Figure 1, Table 1). Twenty compounds amounting to about $100 \%$ of total EO have been identified, where the sesquiterpene hydrocarbon, spiroalkane, and oxide sesquiterpenoid groups were the major groups. The phytochemical composition, retention index (RI), and retention time (RT) with their concentration (\%) are presented in Table 1 and the GC-MS chromatogram (Figure 2).

\subsection{Influence of G. curviflora EO on the Biophysical Gating} Properties of AMPARs. The G. curviflora EO was evaluated for neuroprotective properties against AMPAR-current induction, deactivation, and desensitization rates. The amplitude generated by different AMPA-type receptors was recorded via whole-cell patch technique on HEK293 AMPAR expressing cells. Using glutamate alone, the current produced $(A)$ was then compared to the induced current obtained from glutamate plus EO amplitude $\left(A_{I}\right)$

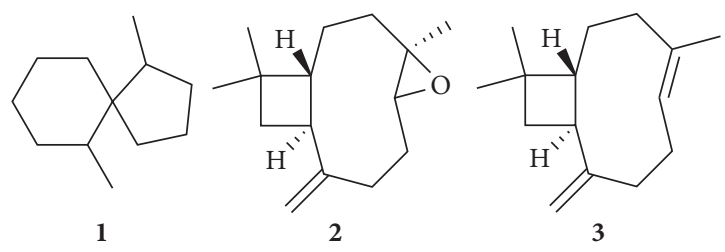

Figure 1: The structure of the major three components in G. curviflora EO.

for calculating any significant inhibition solely from the extract as shown in Figure 3. Preceding the compound treatment, HEK293 cells were normalized for the control via $500 \mathrm{~ms}$ intervals of agonist; the initially acquired amplitude of GluA1, GluA2, GluA1/2, and GluA2/3 was recorded at $964 \pm 55 \mathrm{pA}, 1293 \pm 63 \mathrm{pA}, 490 \pm 31 \mathrm{pA}$, and $452 \pm 39 \mathrm{pA}$, respectively. No significant inhibition was observed by treating the cell with the EO as the amplitude slightly dropped to $812 \pm 26 \mathrm{pA}, 1095 \pm 38 \mathrm{pA}$, $408 \pm 33 \mathrm{pA}$, and $410 \pm 28 \mathrm{pA}$ following the previous order. Nonetheless, the impact of G. curviflora EO on AMPAR desensitization and deactivation was tested. The fast amplitude $(\tau f)$, the slow amplitude $(\tau s)$, and the relative amplitude of both $(\tau f)$ and $(\tau s)$ represented by $(a f)$ were used to attain the weighted tau $(\tau w)$ for AMPAR-current deactivation and desensitization via fitting exponentials. The desensitization before G. curviflora EO treatment for GluA1, GluA2, GuA1/2, and GluA2/3 was $2.8 \pm 0.1 \mathrm{~ms}$, $2.3 \pm 0.1 \mathrm{~ms}, 5.3 \pm 0.2 \mathrm{~ms}$, and $2.5 \pm 0.3 \mathrm{~ms}$, respectively. After treatment, the desensitization significantly increased to $3.7 \pm 0.2 \mathrm{~ms}, 3.9 \pm 0.2 \mathrm{~ms}, 6.8 \pm 0.4 \mathrm{~ms}$, and $3.5 \pm 0.3 \mathrm{~ms}$, respectively. The desensitization rate was $0.27,0.26,0.15$, and 0.28 , respectively. Likewise, the same significant effect of oil on AMPAR deactivation rate was observed, whereby the rate dropped from $0.43 \pm 0.1$, $0.45 \pm 0.1,0.42 \pm 0.3$, and $0.38 \pm 0.2$ to $2.6 \pm 0.3,0.24 \pm 0.2$, $0.21 \pm 0.4$, and $0.26 \pm 0.3$ for GluA1, GluA2, GluA1/2, and GluA2/3, respectively.

3.3. Antimicrobial Activity. The well diffusion procedure was employed in order to assess G. curviflora EO ability to inhibit the growth of S. aureus, MRSA, S. sonnei, E. faecium, E. coli, $P$. aeruginosa, C. albicans, and E. floccosum. The range of concentration of the prepared G. curviflora EO used ranged from 0.025 to $25 \mu \mathrm{g} / \mathrm{mL}$. The attained results revealed that EO displayed significant antibacterial and antifungal effects against all the tested strains as indicated in Table 2. The EO inhibited the growth of the studied bacteria at concentrations of $0.125-6.25 \mu \mathrm{L} / \mathrm{mL}$. It inhibited the growth of tested mold (E. floccosum) at half concertation required for the inhibition of the yeast Candida spp.

3.4. Cyclooxygenase Inhibitory Activity. The COX enzymatic inhibition activity of G. curviflora EO was accomplished using Cayman Chemical ELISA kit no. 560131. The calculated inhibition percentage of COX-2 for the tested EO revealed inhibition activity of $98.4 \%$ and $99.5 \%$ at concentrations of $0.25 \mu \mathrm{g} / \mathrm{mL}$ and $0.5 \mu \mathrm{g} / \mathrm{mL}$, respectively. Similar 
TABLE 1: The chemical composition of N. curviflora essential oil.

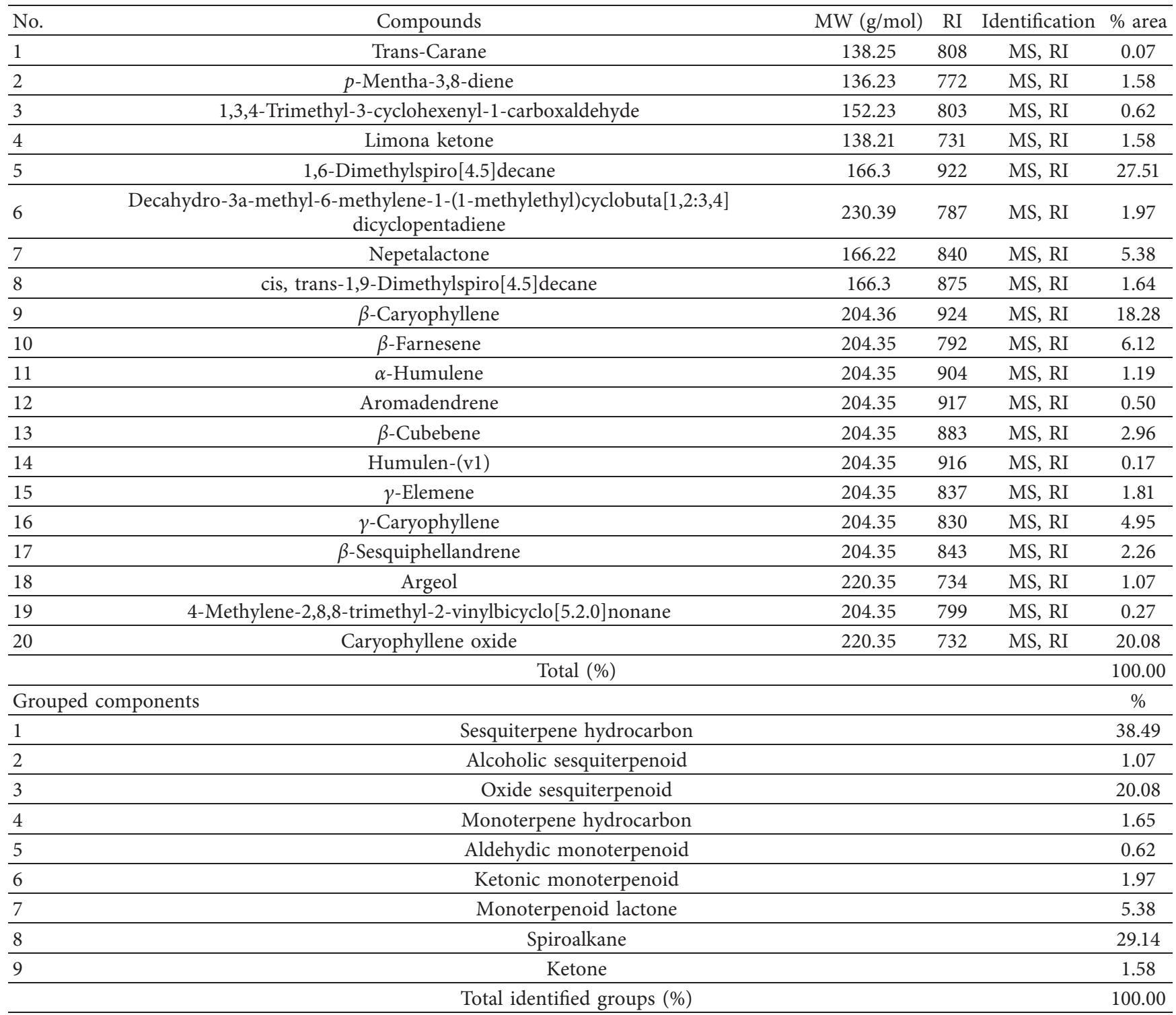

MW: molecular weight; RI: retention index; and RT: retention time.

results were obtained for the inhibition of COX-1, where the inhibition was $98 \%$ and $99 \%$ for the two tested concentrations, respectively. The results revealed that the G. curviflora EO demonstrated a potent but nonselective inhibitory activity towards both COX-2 and COX-1 enzymes.

\section{Discussion}

There are rising interests towards the use of natural biological sources, which are known in general as phytotherapeutic active compounds. The necessity for the search for potential drug candidate from plants is incited by different reasons including the growth of chronic and degenerative diseases, inadequate access to medications, incidents of epidemic antibiotic resistances, and the emergence of new diseases [22-24].
Twenty compounds were identified, accounting for $100 \%$ of the total EO, of which 1,6-dimethylspiro[4.5] decane $\mathbf{1}$, caryophyllene oxide $\mathbf{2}$, and $\beta$-caryophyllene 3 were the most abundant components representing $27.51 \%, 20.08 \%$, and $18.28 \%$, respectively. The twenty components could be classified into eight phytochemical groups, of which sesquiterpene hydrocarbon was the most abundant group (38.49\%), followed by the oxygenated sesquiterpene (caryophyllene oxide) group (20.08\%) and spiroalkane group (29.14\%). The major components of sesquiterpene hydrocarbon were $\beta$-caryophyllene (18.28\%), $\beta$-farnesene (6.2\%), and $\gamma$-caryophyllene $(4.95 \%)$. The comical compositions of EO of $G$. curviflora growing in Lebanese and Jordanian mountains were reported. Musso et al. reported the identification of 49 compounds in the EO extracted from G. curviflora growing in Lebanon, of which 2-isopropyl-5methyl-3-cyclohexen-1-one (12.51\%), (-)-spathulenol 


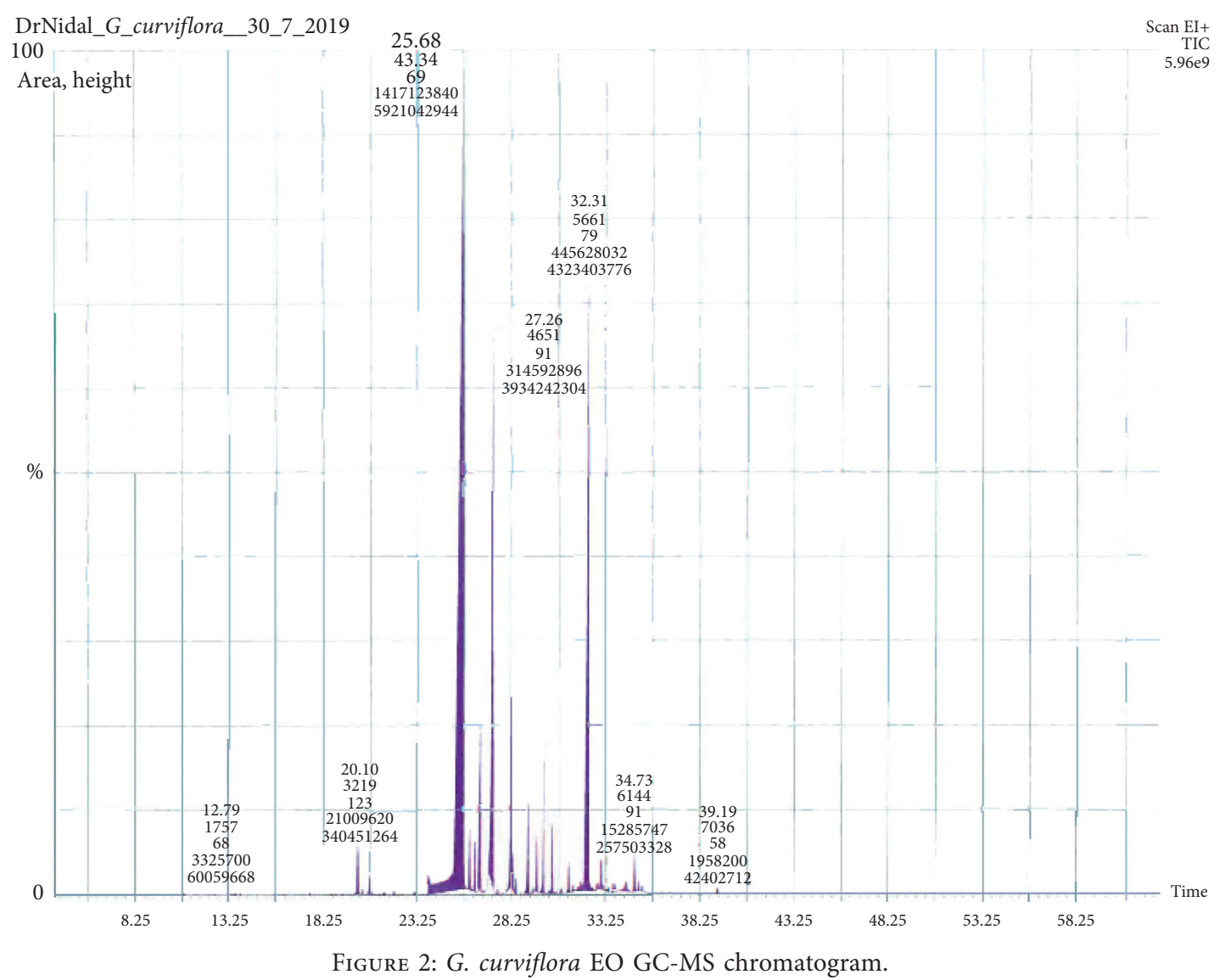

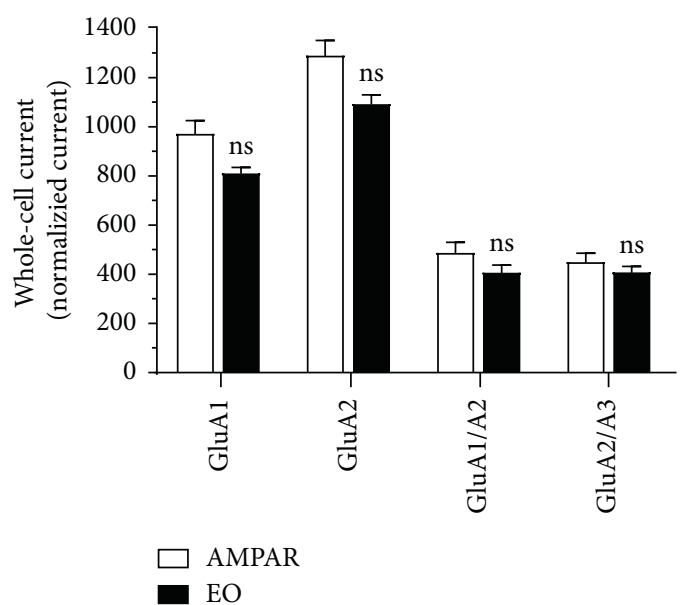

(a)

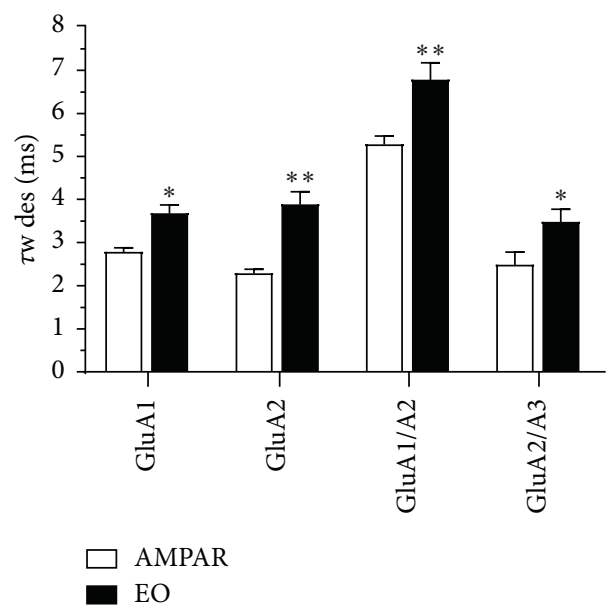

(b)

Figure 3: Continued. 


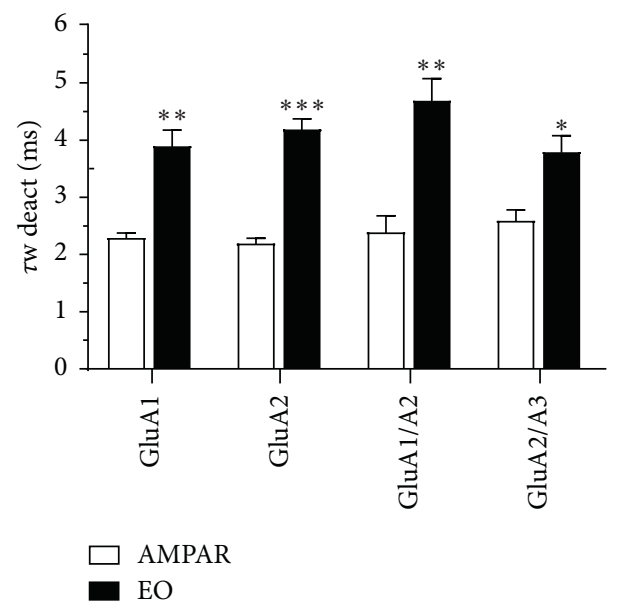

(c)

FIgURE 3: Effect of G. curviflora EO on AMPARs. (a) Whole-cell current recording of AMPAR subtypes with and without G. curviflora EO treatment. The effect of $80 \mu \mathrm{M}$ of G. curviflora EO (black) and $10 \mathrm{mM}$ of glutamate alone (white) on the amplitude generated by different AMPARs. (b) The destination rate of various AMPARs before EO treatment (glutamate alone) vs. after treatment (glutamate + EO). Desensitization via the weighted time constant calculated by the pulses per $500 \mathrm{~ms}$ on the response of Glu alone and Glu + EO. (c) Pulses per $20 \mathrm{~ms}$ on the response of Glu alone and Glu + EO to calculate the deactivation. All trials performed on AMPAR expressing HEK293 cells, where the number of patch whole-cells, $n=5$. One-way ANOVA with the following significance presented the data displayed in the figure: ${ }^{*}<0.05 ;{ }^{* *}<0.01$; and ${ }^{* * *}<0.001$; ns: not significant.

TABle 2: Antimicrobial activities (MICs) of G. curviflora EO ( $\mu \mathrm{g} / \mathrm{mL})$.

\begin{tabular}{lcccc}
\hline Microorganisms & G. curviflora EO & Ampicillin & Ciprofloxacin & Fluconazole \\
\hline S. aureus & 3.12 & 6.25 & 0.78 & 12.5 \\
MRSA & 25 & 0 & 12.5 & 0 \\
S. sonnei & 14 & 20 & 0.78 & 0 \\
E. faecium & 6.25 & 1.56 & 0.78 & 0 \\
E. coli & 1.25 & 3.12 & 3.12 & 0 \\
P. aeruginosa & 1.25 & 0 & 0 & 0 \\
C. albicans & 6.25 & 0 & 0 & 3.12 \\
E. floccosum & 3.12 & 0 & 0.66 \\
\hline
\end{tabular}

(11.73\%), cis-Z- $\alpha$-bisabolene epoxide (8.07\%), widdrol (7.0\%), (E, Z)-5, 7-dodecadiene (6.93\%), dihydronepetalactone (5.57\%), and 4-propyl-cyclohexene (5.43\%) were the major constituents [25]. A study conducted by Al-Qudah on EO from fresh and dry aerial parts of $G$. curviflora from Jordan revealed that fresh one was composed mostly of sesquiterpene hydrocarbons $(55.27 \%)$ whilst air-dried G. curviflora was composed mainly of oxygenated monoterpenes (50.31\%). The main detected compounds from the fresh sample were $\gamma$-muurolene (18.54\%), $4 a \alpha, 7 \alpha, 6 a \alpha$-nepetalactone $\quad(17.76 \%), \quad E$-caryophyllene (16.37\%), $\alpha$-himachalene (5.63\%), $\gamma$-muurolene (4.30\%), and $\beta$-bisabolene (3.22\%), while the major abundant compounds identified in the air-dried sample composed of $4 a \alpha, 7 \alpha, 7 a \alpha$-nepetalactone $\quad(43.85 \%), \quad E$ caryophyllene (11.53\%), and $\gamma$-muurolene (10.47\%) [26].

The qualitative and quantitative variations in the findings could be attributed to the location and collection time and extraction techniques used. In contrast to the previously reported investigation, the mild microwave ultrasonic apparatus for the extraction of the EO was used in the current study. The previously reported studies used the hydrodistillation procedure, which requires reflux for a long time $(\geq 3 \mathrm{~h})$, which can have an impact on the chemical composition of the EO. The plant material used in the current study was collected on the 19th of May, where the previously reported studies worked on a plant collected in April.

Excessive AMPAR activity and upregulation have been implicated with numerous neuropsychiatric disorders and various neurodegenerative diseases such as epilepsy, Parkinson's disease, and ALS [27, 28]. Although the G. curviflora EO did not affect the activation of AMPARs, it displayed neuroprotective properties by targeting the receptor's desensitization and deactivation rate. The EO drastically prolonged the state at which the receptor remains in desensitization and deactivation by lowering the rates and consequently reaches a receptor in a nonactive state or a slow current-induced state. The oil showed activity on all tested AMPAR subtypes, yet significantly enhance the desensitization rate in addition to the deactivation rate of the GluA2 subtype comparable to other subtypes. To confirm this finding, we assessed the open state receptors by using $10 \mathrm{mM}$ 
ligand concentration [3]. While the concentration of the EO was determined through a concentration-dependent curve that defined the plateau level at $80 \mu \mathrm{M}$, a further increase in the concentration had no additional effect on desensitization or deactivation. These results inspire a more significant analysis of the G. curviflora EO neuroprotective properties. Identification of the active components in the oil is essential in order to understand AMPARs function better and synthesize anticonvulsant drugs targeting AMPARs.

The worldwide evolution of antimicrobial resistance, in addition to the scarcity of novel antibiotic medications, represents a serious public health concern. That means the go-back to a preantibiotic epoch in which infectious diseases caused by multiple-resistant microbial pathogens are uncontrollable [29]. It is well documented that EOs displayed a comparable antimicrobial effect against the tested antibioticresistant and antibiotic-susceptible strains; therefore, it could be presumed that the EOs mechanism of action is unlike that from the used antibacterial and antifungal drugs [11]. The antimicrobial activity of the EO extracted from G. curviflora leaves and flowers was assessed using broth microdilution assay. The results revealed that the EO affected all screened bacterial and fungal strains. It displayed potent activity against $P$. aeruginosa with a MIC dose of $1.25 \mu \mathrm{g} / \mathrm{mL}$ compared with the positive controls ampicillin and ciprofloxacin, which have MIC values of 25 and $3.12 \mu \mathrm{g} / \mathrm{mL}$, respectively. $P$. aeruginosa is a Gram-negative bacterium that can cause infection in the respiratory system, urinary tract, wounds, and burns. Furthermore, it can give rise to blood infections causing a series of virulent infectious diseases including diffuse bronchopneumonia, cystic fibrosis, non-CF bronchiectasis, urinary tract catheterization, ecthyma gangrenosum, septic shock, hemorrhage, and necrosis.

The G. curviflora EO displayed twofold greater antibacterial activity than that of Ampicillin (positive control) against $S$. aureus with MIC values of 3.12 and $6.25 \mu \mathrm{g} / \mathrm{mL}$, respectively. On the other hand, it showed twofold weaker anti-MRSA activity than that of ciprofloxacin with MIC values of 25 and $12.5 \mu \mathrm{g} / \mathrm{mL}$, respectively. Moreover, it exhibited potent anti-E. coli activity comparing with ciprofloxacin with MIC values of 1.25 and $0.78 \mu \mathrm{g} / \mathrm{ml}$, respectively. It showed 1.2-fold lower antibacterial activity against $S$. sonnei as compared with that of ciprofloxacin with MIC values of 14 and $12.5 \mu \mathrm{g} / \mathrm{mL}$, respectively. The EO revealed anti-Candida and antimold activities with MIC values of 6.25 and $3.125 \mu \mathrm{g} / \mathrm{mL}$ as compared with the most potent antifungal drug (fluconazole), which has a MIC dose of 3.12 and $0.66 \mu \mathrm{g} / \mathrm{mL}$, respectively. G. curviflora EO displayed powerful activity against $P$. aeruginosa, S. sonnei, E. coli, S. aureus, and MRSA. Our results can be compared with the data reported by Zomorodian et al. on the same strains [30]. They reported that the EO of $N$. cataria displayed a powerful antibacterial activity against MethicillinResistant S. aureus and S. sonnei with MIC values of 0.22 and $2 \mu \mathrm{l} / \mathrm{mL}$, respectively. Furthermore, a study conducted by Shakeri et al. revealed that EO possesses antibacterial activity against $P$. aeruginosa and $S$. aureus with MIC values of 150 and $14 \mu \mathrm{g} / \mathrm{mL}$, respectively [31].
Some reports attributed the decent antibacterial activities to the high concentration of bicyclic terpenoid nepetalactone, identified as major compounds of various Nepeta species $[32,33]$. Furthermore, in vitro studies showed that EOs rich in caryophyllene isomers and caryophyllene oxide displayed significant antimicrobial activity, suggesting that the substances possibly participated in this activity [34]. Da Costa et al. found out that Lantana camara EO, of which $\beta$-caryophyllene is the major component (31.5\%), exhibited significant antimicrobial activity, especially against P. vulgaris (ATCC 13315) and E. coli (ATCC 25922) [34]. In agreement with our results, Maia et al. reported that EOs of Vernonia remotiflora and $V$. brasiliana, both rich in $\beta$-caryophyllene $(\approx 40 \%)$, inhibited the growth of several tested Gram-negative and Gram-positive bacteria, including S. aureus and P. aeruginosa [35]. Ghosh et al. [36] evaluated the activity of essential oils of Alpinia nigra (47.7 to $49 \%$ of $\beta$-caryophyllene) against Gram-positive and Gram-negative bacteria. The lowest MIC was found against Yersinia enterocolitica $(1.56 \mu \mathrm{L} / \mathrm{mL})$.

Cyclooxygenases (COX), known as prostaglandin $\mathrm{H}_{2}$ synthases, catalyze the first phase in the biosynthesis of the Nonsteroidal Anti-Inflammatory Drugs (NSAIDs) prostaglandins (PGs) and thromboxanes [37]. Most of the commonly used NSAIDs have various harmful side effects including ringing in the ear, heartburn, stomach pain, hemorrhage, dizziness, headaches, allergic reactions, kidney or liver problems, hyperglycemia, and high blood pressure [38].

The in vitro COX inhibitory assay revealed potent inhibitory activity of G. curviflora EO as compared with celecoxib, but nonselective towards both COX-1 and COX-2 enzymes with $\mathrm{IC}_{50}$ values of $0.069 \pm 0.001$ and $0.074 \pm 0.0015 \mu \mathrm{g} / \mathrm{mL}$, respectively, which is around 10 -fold greater than that of celecoxib $\left(\mathrm{IC}_{50}=0.55 \pm 0.0012 \mu \mathrm{g} / \mathrm{mL}\right.$ for COX-1 and $0.6 \pm 0.0015 \mu \mathrm{g} / \mathrm{mL}$ for COX-2). Jeppesen et al. reported that EO of $N$. parmiriensis displayed COX-1 inhibitory effect with $45,85,75$, and $91 \%$ inhibition at concentrations of $0.05,0.5,5,50$, and $500 \mu \mathrm{g} / \mathrm{mL}$, respectively, whilst G. curviflora EO showed $99 \%$ of COX-1 inhibitory action at the $0.5 \mu \mathrm{g} / \mathrm{mL}$ dose which is superior to that of $N$. parmiriensis [39]. Our findings suggest that the EO of G. curviflora due to its potent anti-inflammatory potential, which similar to that COX-inhibitory effect of the drug celecoxib that has several adverse reactions [40], could be considered as an alternative option.

\section{Conclusion}

The current investigation explored the chemical ingredients of G. curviflora VO, which revealed the presence of twenty phytochemicals, of which 1,6-dimethylspiro[4.5]decane $\mathbf{1}$, caryophyllene oxide 2 , and $\beta$-caryophyllene 3 were the major compounds. The G. curviflora VO displayed potent antimicrobial as compared with ciprofloxacin, Ampicillin, and fluconazole. Moreover, it showed potential cyclooxygenase inhibitory activity compared with celecoxib and has potential neuroprotective activity effect. However, further studies in vivo and clinical trial investigations are required to 
approve these findings and to establish suitable pharmaceutical formulations to be used as formal drugs or food supplements based on the G. curviflora VO.

\section{Data Availability}

All the utilized data to support the findings of the current study are included in the article.

\section{Conflicts of Interest}

The authors declare that they have no conflicts of interest regarding the publication of this paper.

\section{Authors' Contributions}

All authors contributed equally to this research.

\section{Acknowledgments}

The authors wish to thank An-Najah National University.

\section{References}

[1] C. Egbuna, S. Kumar, J. C. Ifemeje, S. M. Ezzat, and S. Kaliyaperumal, Phytochemicals as Lead Compounds for New Drug Discovery, Elsevier, London, UK, 2019.

[2] M. Tanveer, C. Wagner, M. I. Ul Haq et al., "Spicing up gastrointestinal health with dietary essential oils," Phytochemistry Reviews, vol. 19, no. Suppl 1, 2020.

[3] M. Qneibi, O. Hamed, O. Fares et al., "The inhibitory role of curcumin derivatives on AMPA receptor subunits and their effect on the gating biophysical properties," European Journal of Pharmaceutical Sciences, vol. 136, Article ID 104951, 2019.

[4] B. Li and T. J. Webster, "Bacteria antibiotic resistance: new challenges and opportunities for implant-associated orthopedic infections," Journal Orthopaedic Research, vol. 36, no. 1, pp. 22-32, 2018.

[5] N. Jaradat, S. Al-lahham, M. N. Abualhasan et al., "Chemical constituents, antioxidant, cyclooxygenase inhibitor, and cytotoxic activities of Teucrium pruinosum boiss. Essential oil," BioMed Research International, vol. 2018, Article ID 4034689, 9 pages, 2018.

[6] H. Suleyman, B. Demircan, and Y. Karagoz, "Anti-inflammatory and side effects of cyclo-oxygenase inhibitors," Pharmacological Reports, vol. 59, no. 3, pp. 247-258, 2007.

[7] A. G. Al-Bakri and F. U. Afifi, "Evaluation of antimicrobial activity of selected plant extracts by rapid XTT colorimetry and bacterial enumeration," Journal of Microbiological Methods, vol. 68, no. 1, pp. 19-25, 2007.

[8] A. Ali, N. Tabanca, B. Demirci et al., "Chemical composition and biological activity of essential oils from four Nepeta species and hybrids against Aedes aegypti (L.) (Diptera: Culicidae)," Records Natural Product, vol. 10, no. 2, pp. 137-147, 2016.

[9] A. Sharma and D. S. Cannoo, "Phytochemical composition of essential oils isolated from different species of genus Nepeta of Labiatae family: a review," Pharmacophore, vol. 47, no. 6, pp. 181-211, 2013.

[10] N. A. Jaradat, S. Al-lahham, A. N. Zaid et al., "Carlina curetum plant phytoconstituents, enzymes inhibitory and cytotoxic activity on cervical epithelial carcinoma and colon cancer cell lines," European Journal of Integrative Medicine, vol. 30, Article ID 100933, 2019.

[11] M. Shehadeh, N. Jaradat, M. Al-Masri et al., "Rapid, costeffective and organic solvent-free production of biologically active essential oil from Mediterranean wild Origanum syriacum," Saudi Pharmaceutical Journal, vol. 27, no. 5, pp. 612-618, 2019.

[12] M. Vinaixa, E. L. Schymanski, S. Neumann, M. Navarro, R. M. Salek, and O. Yanes, "Mass spectral databases for LC/ MS- and GC/MS-based metabolomics: state of the field and future prospects," TrAC Trends in Analytical Chemistry, vol. 78, pp. 23-35, 2016.

[13] X. Wei, I. Koo, S. Kim, and X. Zhang, "Compound identification in GC-MS by simultaneously evaluating the mass spectrum and retention index," The Analyst, vol. 139, no. 10, pp. 2507-2514, 2014.

[14] M. Qneibi, O. Hamed, A.-R. Natsheh et al., "Inhibition and assessment of the biophysical gating properties of GluA2 and GluA2/A3 AMPA receptors using curcumin derivatives," PLoS One, vol. 14, no. 8, Article ID e0221132, 2019.

[15] M. Qneibi, N. Jaradat, and N. Emwas, "Effect of geraniol and citronellol essential oils on the biophysical gating properties of AMPA receptors," Applied Sciences, vol. 9, no. 21, p. 4693, 2019.

[16] M. Qneibi, N. Jaradat, M. Hawash et al., "The neuroprotective role of Origanum syriacum L. and Lavandula dentata L. essential oils through their effects on AMPA receptors," BioMed Research International, vol. 2019, Article ID 5640173, 11 pages, 2019.

[17] B. A. Forbes, D. F. Sahm, and A. S. Weissfeld, Study Guide for Bailey \& Scott's Diagnostic Microbiology, Mosby, Maryland Heights, MI, USA, 2007.

[18] M. A. Wikler, Performance Standards for Antimicrobial Susceptibility Testing: Seventeenth Informational Supplement, Clinical and Laboratory Standards Institute, Wayne, PA, USA, 2007.

[19] B. A. Forbes, D. F. Sahm, and A. S. Weissfeld, Study Guide for Bailey and Scott's Diagnostic Microbiology, Elsevier Health Sciences, London, UK, 2016.

[20] M. E. Klepser, E. J. Wolfe, R. N. Jones, C. H. Nightingale, and M. A. Pfaller, "Antifungal pharmacodynamic characteristics of fluconazole and amphotericin B tested against Candida albicans," Antimicrobial Agents and Chemotherapy, vol. 41, no. 6, pp. 1392-1395, 1997.

[21] M. Falahati, N. O. Tabrizib, and F. Jahaniani, "Anti dermatophyte activities of Eucalyptus camaldulensis in comparison with Griseofulvin," Iranian Journal of Pharmacology \& Therapeutics, vol. 4, no. 2, pp. 80-83, 2005.

[22] K. Ramawat, S. Dass, and M. Mathur, The Chemical Diversity of Bioactive Molecules and Therapeutic Potential of Medicinal Plants, Herbal Drugs: Ethnomedicine to Modern Medicine, pp. 7-32, Springer, Berlin, Germany, 2009.

[23] A.-M. Reid, C. B. Oosthuizen, B. D. Fibrich et al., Traditional Medicine: The Ancient Roots of Modern Practice, Medicinal Plants for Holistic Health and Well-Being, pp. 1-11, Elsevier, Amsterdam, Netherlands, 2018.

[24] A. Srivastava, P. Srivastava, A. Pandey, V. Khanna, and A. Pant, Phytomedicine: A Potential Alternative Medicine in Controlling Neurological Disorders, New Look to Phytomedicine, pp. 625-655, Elsevier, Amsterdam, Netherlands, 2019.

[25] L. Musso, B. Scaglia, G. A. Haj et al., "Chemical characterization and nematicidal activity of the essential oil of Nepeta nuda L. ssp. pubescens and Nepeta curviflora Boiss. from 
Lebanon," Journal of Essential Oil Bearing Plants, vol. 20, no. 6, pp. 1424-1433, 2017.

[26] M. A. Al-Qudah, "Antioxidant acitvity and chemical composition of essential oils of fresh and air-dried Jordanian Nepeta curviflora Boiss," Journal of Biologically Active Products from Nature, vol. 6, no. 2, pp. 101-111, 2016.

[27] S. S. Mousa and M. Dikshit, "AMPA receptor regulation mechanisms: future target for safer neuroprotective drugs," International Journal of Neuroscience, vol. 114, no. 6, pp. 695-734, 2004.

[28] S. Kwak and J. H. Weiss, "Calcium-permeable AMPA channels in neurodegenerative disease and ischemia," Current Opinion in Neurobiology, vol. 16, no. 3, pp. 281-287, 2006.

[29] N. Jaradat, N. Shawarb, F. Hussein et al., "Antibacterial and antioxidant screening of semi-synthetic naringin based hydrazone and oxime derivatives," Jundishapur Journal Microbiology, vol. 11, no. 6-12, 2018.

[30] K. Zomorodian, M. J. Saharkhiz, S. Shariati, K. Pakshir, M. J. Rahimi, and R. Khashei, "Chemical composition and antimicrobial activities of essential oils from Nepeta cataria L. Against common causes of food-borne infections," ISRN Pharmaceutics, vol. 2012, Article ID 591953, 6 pages, 2012.

[31] A. Shakeri, F. Khakdan, V. Soheili, A. Sahebkar, G. Rassam, and J. Asili, "Chemical composition, antibacterial activity, and cytotoxicity of essential oil from Nepeta ucrainica L. spp. kopetdaghensis," Industrial Crops and Products, vol. 58, pp. 315-321, 2014.

[32] C. Bourrel, F. Perineau, G. Michel, and J. M. Bessiere, "Catnip (Nepeta cataria L.) essential oil: analysis of chemical constituents, bacteriostatic and fungistatic properties," Journal of Essential Oil Research, vol. 5, no. 2, pp. 159-167, 1993.

[33] L. Zenasni, H. Bouidida, A. Hancali et al., "The essentials oils and antimicrobial activity of four Nepeta species from Morocco," Journal Medicinal Plant Research, vol. 2, no. 5, pp. 111-114, 2008.

[34] J. G. M. D. Costa, E. O. D. Sousa, F. F. G. Rodrigues, S. G. D. Lima, and R. Braz-Filho, "Composição química e avaliação das atividades antibacteriana e de toxicidade dos óleos essenciais de Lantana camara L. e Lantana sp," Revista Brasileira de Farmacognosia, vol. 19, no. 3, pp. 710-714, 2009.

[35] A. I. V. Maia, M. C. M. Torres, O. D. L. Pessoa et al., "Óleos essenciais das folhas de Vernonia Remotiflora e Vernonia Brasiliana: composição química e atividade biológica," Química Nova, vol. 33, no. 3, pp. 584-586, 2010.

[36] S. Ghosh, T. Ozek, N. Tabanca et al., "Chemical composition and bioactivity studies of Alpinia nigra essential oils," Industrial Crops and Products, vol. 53, pp. 111-119, 2014.

[37] N. Jaradat and N. Al-Maharik, "Fingerprinting, antimicrobial, antioxidant, anticancer, cyclooxygenase and metabolic enzymes inhibitory characteristic evaluations of stachys viticina boiss. Essential oil,” Molecules, vol. 24, no. 21, p. 3880, 2019.

[38] N. Moore, "Coronary risks associated with diclofenac and other NSAIDs: an update," Drug Safety, vol. 18, pp. 1-18, 2020.

[39] A. S. Jeppesen, J. Soelberg, and A. K. Jäger, "Antibacterial and COX-1 inhibitory effect of medicinal plants from the pamir mountains, Afghanistan," Plants, vol. 1, no. 2, pp. 74-81, 2012.

[40] M. B. Levy and J. N. Fink, "Anaphylaxis to celecoxib," Annals of Allergy, Asthma \& Immunology, vol. 87, no. 1, pp. 72-73, 2001. 